\title{
Crystal structure of a G-1 dendrimer of aminoisophtalic acid
}

Juan V. Trillo, Santiago de Frutos, Francisco Meijide, Victor H. Soto, ${ }^{\#}$ Aida Jover, and José Vázquez Tato

Departamento de Química Física, Facultad de Ciencias, Universidad de Santiago de Compostela, Avda. Alfonso X El Sabio s/n, 27002 Lugo, Spain

\#Escuela de Química, Centro de Investigación en Electroquímica y Energía Química (CELEQ), Universidad de Costa Rica, San José, Costa Rica

\begin{abstract}
The G-1 dendrimer 4,4',4",4"'-methanetetrayltetrakis(N-(3,5-dicarboxyphenyl)benzamide) has been obtained from 4,4',4",4'"-methanetetrayltetrabenzoic acid and isophtalic acid. The compound was recrystallized from methanol and its structure resolved. The crystal belongs to the tetragonal crystal system space group I-4 $2 \mathrm{~d}$, the cell lengths being $a=b=18.9585(16) \AA$, and $c=23.703(2) \AA$. The crystal structure evidences the formation of cavities. Only one type of hydrogen bond is observed implying the nitrogen atom (acting as donor) and the oxygen atom of one carboxy group of the aminoisophtalic residue (as acceptor), while the other carboxy group does not participate in the network. The donor-acceptor distance is 3.024(2) A.
\end{abstract}

\section{Introduction}

Crystals are described by translation of the unit cell into all three directions of space, but by considering them as supramolecular entities, they may be analyzed them in terms of networks. This way of analyzing molecular crystals is called molecular tectonics. ${ }^{1}$ Consequently, molecular tectonics is a supramolecular construction using tectonic subunits ${ }^{2}$ and, according to Wang et $a l^{2}$ a tecton is a molecule whose interactions are dominated by specific attractive forces that induce the assembly of aggregates with controlled geometries. Therefore, tectons are active building units bearing recognition information and thus capable of recognizing each other, ${ }^{1}$ and consist 
of multiple peripheral sticky sites linked to a core that holds them in a suitable orientation. $^{3}$

Tetraphenylmethane may be considered as a reference molecule in designing tetrapodal tectons. Its crystal structure was first reported by Sumsion and McLachlan in $1950,{ }^{4}$ and latter refined by Robbins et al. ${ }^{5}$ The X-ray diffraction studies showed that the crystal is tetragonal, space group $P \overline{4} 2_{1}$ c, with unequal central valence angles, not far from the tetrahedral ones. Several tectons were designed by linking functional groups to the aromatic rings. Examples are hydroxy, ${ }^{6}$ halogens,${ }^{7}$ carboxy ${ }^{8}$ ethynylpyridinone, ${ }^{9}$ and acetamido and aminobenzamido ${ }^{10}$ groups, whose crystal structures have been resolved. The resulting crystal structures, where hydrogen bonding, coordination to metals or weak interactions play a decisive role, usually have large chambers. ${ }^{8}$

The central carbon atom has been substituted by $\mathrm{Si}, \mathrm{Sn}$ and $\mathrm{Pb},{ }^{2,6,11-12}$ and other central nuclei or cores may be used as well. Adamantyl tetrapodal core, ${ }^{13-14} 2,2^{\prime}, 6,6^{\prime}-$ tetracarboxybiphenyl, ${ }^{15}$ and the pentaerythrityl-tetraphenil ether ${ }^{3,16}$ are nice examples. Alternative residues to the phenyl moities which constitute the four branches ${ }^{17}$ have also been used for, as well as other cores with different podal degrees. ${ }^{18}$

Dendrimers differ from classical polymers by their symmetry, starburst branching and terminal functionality density. ${ }^{19}$ Synthetic methodologies rely on two approaches described as divergent and convergent. ${ }^{19-21}$ The divergent method consists on the sequential addition of repeating units to a starting core (normally a small molecule or ion), thus forming shells or generations. Dendrimers are of great interest as carriers of functional groups, ${ }^{22}$ the number of which depends on the number of branches at the core (core multiplicity); the number of branches on each monomer repeating unit, and the number of generations. Different cores, particularly with different number of functionalities, have been used. ${ }^{23}$

The crystal structure of tetrakis(4-carboxyphenyl)methane have been reported by Malek et $\mathrm{al}^{8}$ as well as the structure of the silane analogous. ${ }^{11}$ To this core, four aminoisophalic groups were attached forming a G-1 dendrimer which exhibits eight carboxy groups in the surface. In this communication, the crystal structure of 4,4',4",4"'methanetetrayltetrakis(N-(3,5-dicarboxy-phenyl)benzamide), in which four aminoisophtalic units are linked to the core tetrakis(4-carboxyphenyl)methane is presented. 


\section{Experimental}

Thyonil chloride was used as received from Aldrich. 1,4-dioxane was from Panreac and dried over sodium/benzophenone. The core tetrakis(4carboxyphenyl)methane was obtained according to literature procedures. ${ }^{24-25}$ The final compound was obtained according to the scheme of Figure 1.

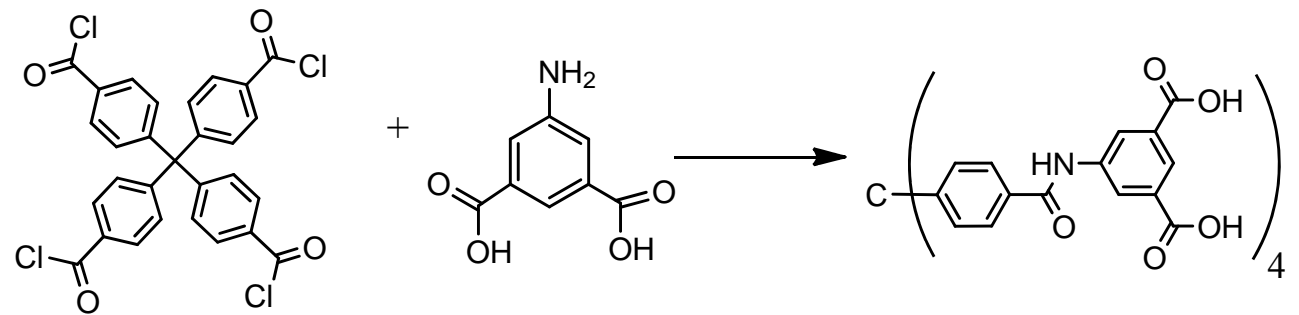

Figure 1. Synthesis of 4,4',4",4"'-methanetetrayltetrakis(N-(3,5-dicarboxy-phenyl) benzamide).

Synthesis of 4,4',4",4"'-methanetetrayltetrabenzoyl chloride: A mixture of tetrakis(4carboxyphenyl)methane $(0.34 \mathrm{~g}, 0.68 \mathrm{mmol})$ and $15 \mathrm{~mL}$ of thionyl chloride was heated to and held at a gentle reflux until all the solids were dissolved. Then, excess of thionyl chloride was removed under reduced pressure. The product obtained was used without further purification.

Synthesis of 4,4',4",4"'-methanetetrayltetrakis(N-(3,5-dicarboxy-phenyl)benzamide): A mixture of 4,4',4",4'"-methanetetrayltetrabenzoyl chloride $(0.39 \mathrm{~g}, 0.68 \mathrm{mmol})$ and amino isophthalic acid $(0.54 \mathrm{~g}, 2.99 \mathrm{mmol})$ in $10 \mathrm{~mL}$ of dry dioxane was refluxed under $\mathrm{N}_{2}$ atmosphere for 24 hours. Dioxane was evaporated under reduced pressure and $100 \mathrm{~mL}$ of water was added to the residue. The suspension was stirred for $15 \mathrm{~min}$, filtered and washed with water $(3 \times 50 \mathrm{~mL})$ and dried under vacumm for 12 hours. Yield, $50 \%$.

${ }^{1} \mathrm{H}$ and ${ }^{13} \mathrm{C}$ NMR spectra were recorded on a Brucker AC-300 MHz. ${ }^{1} \mathbf{H}$ NMR (300 MHz, $\mathbf{d}_{6}$-DMSO, $\delta$ /ppm): 10,43 (s, 4H, -NH); 8,61 (s, 8H $\left.\mathrm{H}_{\mathrm{ar}}\right) ; 8,21\left(\mathrm{~s}, 4 \mathrm{H}_{\mathrm{ar}}\right) ; 8,00-7,98\left(\mathrm{~d}, 8 \mathrm{H}, J_{\text {orto }}=\right.$ 8,15Hz), 7,52-7,49 (d, 8H, $\left.J_{\text {orto }}=8,18 \mathrm{~Hz}\right) .{ }^{13} \mathbf{C}$ NMR (75 MHz, d $\mathbf{d}_{6}$-DMSO, $\left.8 / \mathbf{p p m}\right): 167,11$ $(\mathrm{COOH}) ; 166,15$ (CONH); 149,76; 140,48; 133,47; 132,56; 130,99; 128,37; 125,75; 125,56; 65,89 .

Crystals were obtained from slow evaporation from hot methanol. Data for a colorless prismatic crystal of the compound were collected on a Bruker APPEX-IICCD-1000. Molecular graphics were from Mercury (http://www.ccdc.cam.ac.uk/prods/mercury). A summary of the crystal data and experimental details are listed in Table 1. 
Table 1.-. Crystal data of 4,4',4",4"'-methanetetrayltetrakis(N-(3,5-dicarboxy-phenyl)benzamide).

\begin{tabular}{|c|c|c|c|}
\hline Empirical formula & $\mathrm{C}_{61} \mathrm{H}_{40} \mathrm{~N}_{4} \mathrm{O}_{20}$ & Absorption coefficient $\left(\mathrm{mm}^{-1}\right)$ & 0,068 \\
\hline Formula weight & 1148,99 & $\mathrm{~F}(000)$ & 2376 \\
\hline Temperature $(\mathrm{K})$ & $100(2)$ & Crystal size $\left(\mathrm{mm}^{3}\right)$ & $0,30 \times 0,25 \times 0,14$ \\
\hline Wavelength $(\AA)$ & 0,71073 & Theta range (data collection) $\left(^{\circ}\right)$ & 1,38 to $26,46^{\circ}$ \\
\hline Crystal system & Tetragonal & Index ranges & $\begin{array}{l}-16 \leq \mathrm{h} \leq 16- \\
23 \leq \mathrm{k} \leq 23- \\
29 \leq 1 \leq 29\end{array}$ \\
\hline Space group & $\mathrm{I}-42 \mathrm{~d}$ & Data/ restraints/ parameters & $2402 / 1 / 196$ \\
\hline $\mathrm{a}(\AA)$ & $18,9585(16)$ & Goodnes of fit on $\mathrm{F}^{2}$ & 1,113 \\
\hline $\mathrm{b}(\AA)$ & $18,9585(16)$ & Final $R$ indices $[\mathrm{I}>2 \sigma(\mathrm{I})]$ & $\begin{array}{l}\mathrm{R} 1=0,0342 \\
\mathrm{wR} 2=0,1049\end{array}$ \\
\hline $\mathrm{c}(\AA)$ & $23,703(2)$ & $\mathrm{R}$ indices (all data) & $\begin{array}{l}\mathrm{R} 1=0,0377 \\
\mathrm{wR} 2=0,1065\end{array}$ \\
\hline$\alpha, \beta, \gamma\left({ }^{\circ}\right)$ & $90^{\circ}$ & Extinction coefficient & $2,2(12)$ \\
\hline Volume $\left(\AA^{3}\right)$ & $8519,6(12)$ & Largest diff peak and hole/ $\left(\mathrm{e} \AA^{-3}\right)$ & 0,168 y $-0,299$ \\
\hline $\begin{array}{l}\text { Z/ calculated density } \\
\left(\mathrm{g} / \mathrm{cm}^{3}\right)\end{array}$ & 0,896 & & \\
\hline
\end{tabular}

\section{Results and discussion}

The tetrahedral geometry of the molecule is shown in Figure 2, together with all hydrogen bonds (dot red lines) in which it participates.
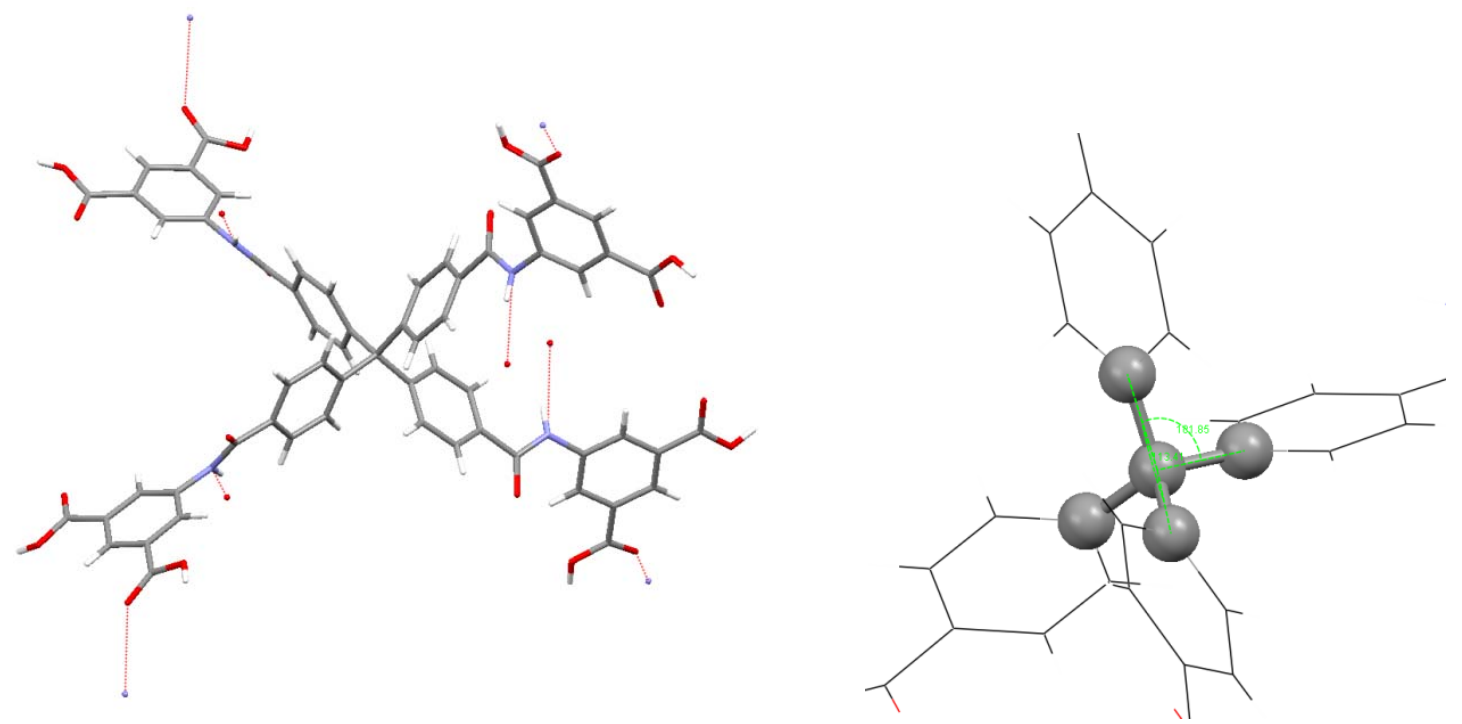

Figure 2. (Left) Structure of 4,4',4",4"'-methanetetrayltetrakis(N-(3,5-dicarboxy-phenyl)benzamide) in the crystal. (Right) Detail of the central carbon atom.

The central atom of the molecule is a tetrahedral carbon atom and consequently a diamondoid crystal structure results. ${ }^{26}$ The C-C-C angles are either 113.4 or $101.9^{\circ}$, far from the tetrahedral value (Figure 2, right). The aromatic rings directly bonded to the central atom are quasi-planar, the maximum distance from any carbon atom to the plane being $0.005 \AA$. On the other hand, these distances are higher in the isophtalic rings, now 
reaching a maximum distance value of $0.019 \AA$. The angle between interior aromatic rings planes are either $88.9^{\circ}$ or $60.8^{\circ}$. The angle between the two aromatic rings planes belonging to the same branch is $70.9^{\circ}$.

Figure 3 shows the crystal packing along the $b$ and $c$ crystallographic axes. The packing along the $a$ axis is equal to the packing along $b$ but rotated $90^{\circ}$.
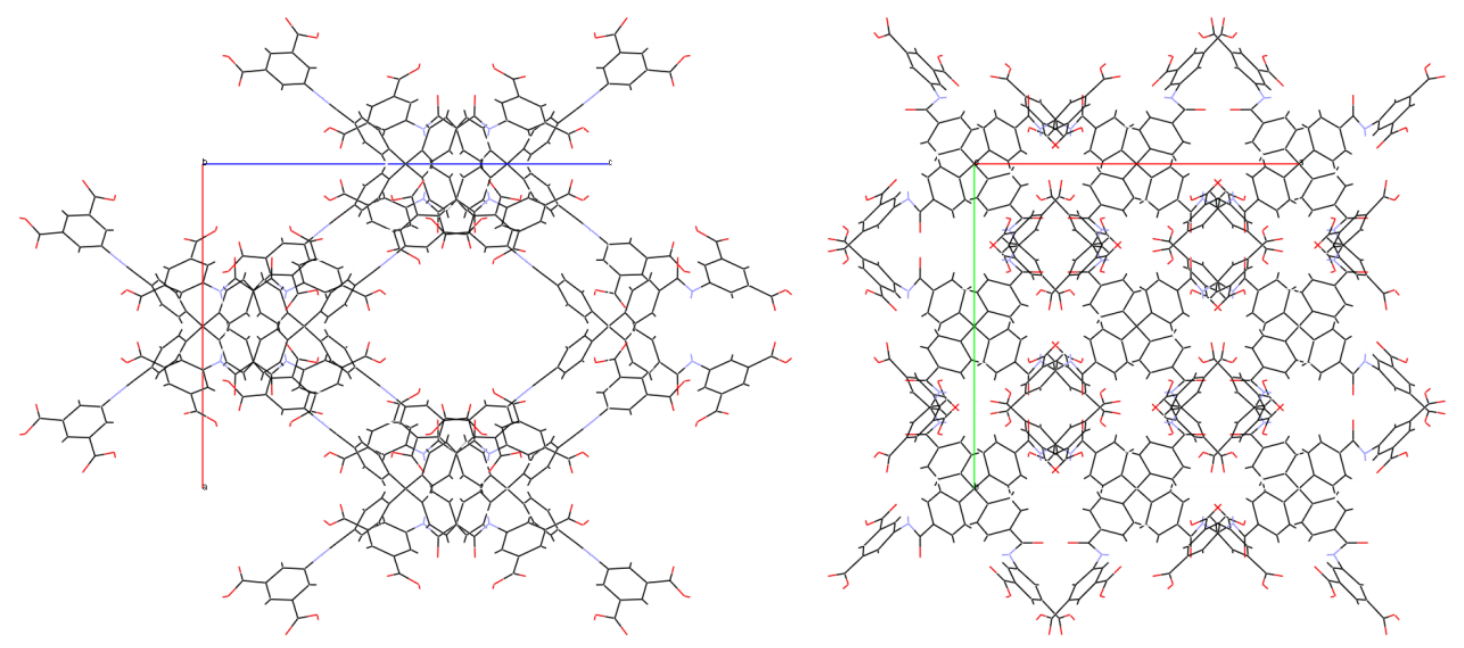

Figure 3. View of the molecular packing in the crystals of 4,4',4",4"'-methanetetrayltetrakis(N-(3,5dicarboxy-phenyl)benzamide) along the crystallographic axes $b$ (left) and (right).

Figure 3 evidences the formation of channels along the $a$ and $b$ axes. Figure 4 shows an enlarged view of the cross section along $b$ (or equivalently along a). The cross section is an almost perfect elipse with radius values of $6.1 \AA$ and $3.7 \AA$, giving an area of $71 \AA^{2}$. A wide range of cross sections values have been observed for closely related tectons. Table 2 resumes some results.

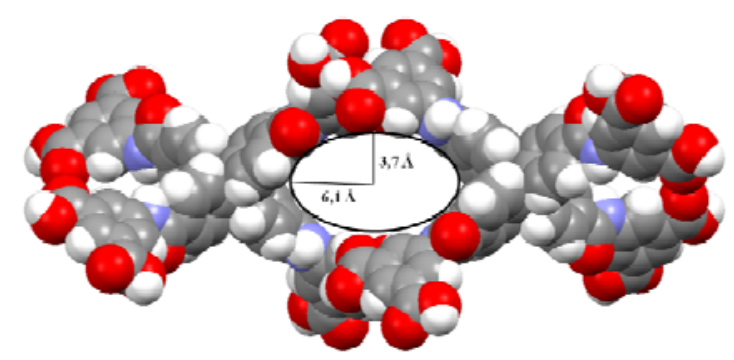

Figure 4. Cross section of channels formed along the $a$ and $b$ axes. 
Table 2. Published cross sections for several tecton crystals.

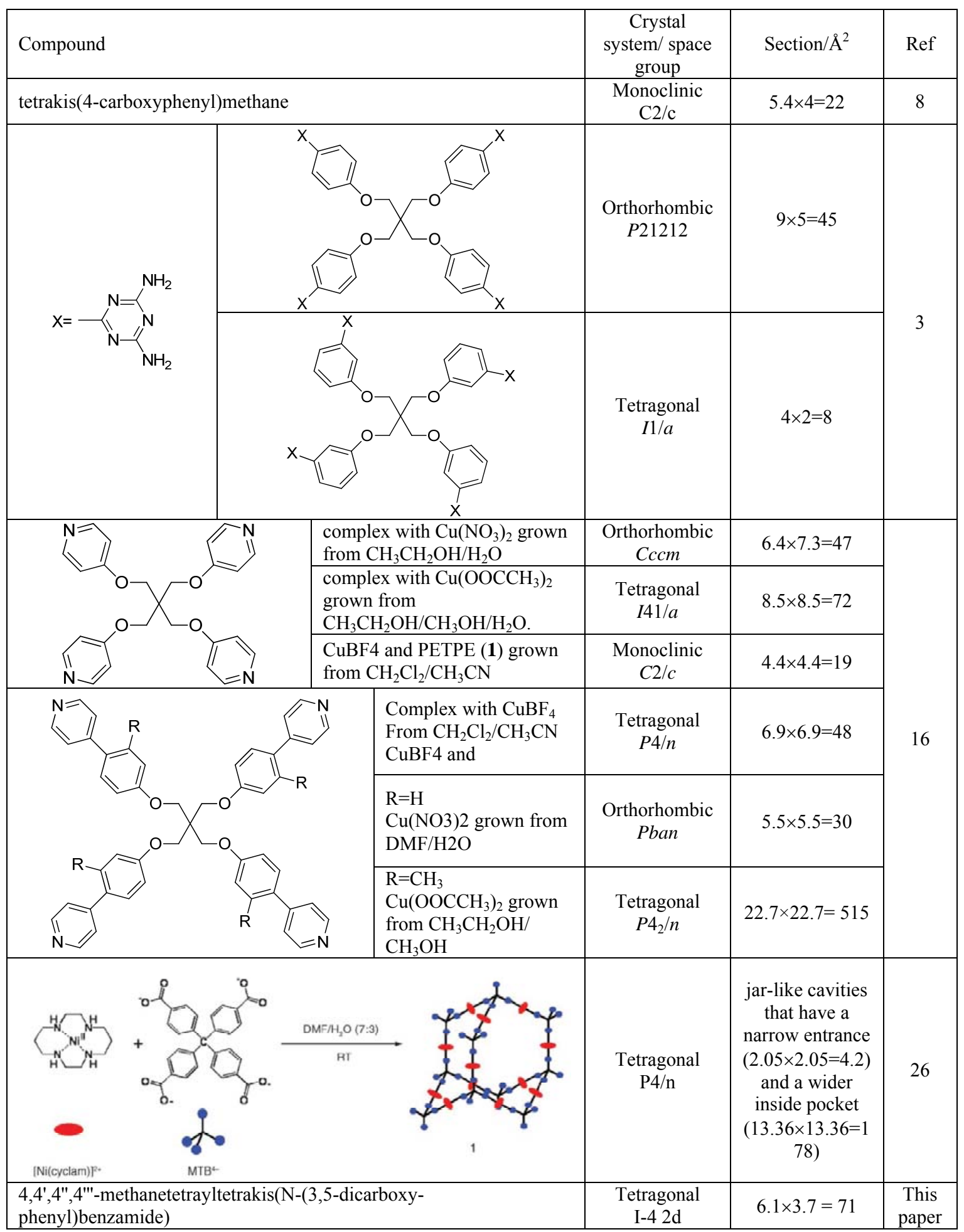

In spite of the number of possible donor/acceptor hydrogen bond sites, each branch of the molecule is only bonded to other two molecules through $\mathrm{N}-\mathrm{H} \rightarrow \mathrm{O}$ hydrogen bonds. It is to say, only one type of hydrogen bond is observed implying the nitrogen atom (acting as donor) and the oxygen atom of one carboxy group of the 
aminoisophtalic residue (as acceptor), while the other carboxy group does not participate in the network. The geometric parameters of the hydrogen bond are shown in Table 3.

Table 3. Geometric parameters of the $\mathrm{N}-\mathrm{H} \rightarrow \mathrm{O}$ hydrogen bond.

\begin{tabular}{ccccc} 
Donor $-\mathrm{H} \cdot$ Acceptor & $\mathrm{D}-\mathrm{H}$ & $\mathrm{H} \cdot \mathrm{A}$ & $\mathrm{D} \cdot \mathrm{A}$ & Angle D-H A \\
\hline $\mathrm{N}(1)-\mathrm{H}(1) \cdots \mathrm{O}(2)$ & $0.863(18)$ & $2.185(18)$ & $3.024(2)$ & $164(2)$
\end{tabular}

The distance between the central carbon atoms of molecules connected through hydrogen bonds is $17.893 \AA$.

\section{Acknowledgements}

The authors thank the Ministerio de Ciencia y Tecnología, Spain, (Projects MAT2007-61721 and MAT2010-19440) for financial support. J. V. Trillo also thanks for a scholarship.

\section{References}

(1) Hosseini, M. W. Acc. Chem. Res. 2005, 38, 313.

(2) Wang, X.; Simard, M.; Wuest, J. D. J. Am. Chem. Soc. 1994, 116, 12119.

(3) Laliberte, D.; Maris, T.; Wuest, J. D. J. Org. Chem 2004, 69, 1776.

(4) Sumsion, H. T.; McLachlan, D., Jr. Acta Crystal. 1950, 3, 217.

(5) Robbins, A.; Jeffrey, G. A.; Chesick, J. P.; Donohue, J.; Cotton, F. A.; Frenz, B. A.; Murillo, C. A. Acta Crystal. 1975, B31, 2395.

(6) Fournier, J.-H.; Maris, T.; Simard, M.; Wuest, J. D. Crystal Growth Des. 2003, 3, 535.

(7) Thaimattam, R.; Shekhar Reddy, D.; Xue, F.; Mak, T. C. W.; Nangia, A.; Desiraju, G. R. New J. Chem. 1998, 22, 43.

(8) Malek, N.; Maris, T.; Simard, M.; Wuest, J. D. Acta Crystal. E 2005, 61, 0518.

(9) Simard, M.; Su, D.; Wuest, J. D. J. Am. Chem. Soc. 1991, 113, 4696.

(10) Lorenzi, G. P.; Manessis, A.; Tirelli, N. C.; Gramlich, V. Struct. Chem. 1997, 8, 435.

(11) Lambert, J. B.; Zhao, Y.; Stern, C. L. J. Phys. Org. Chem. 1997, 10, 229.

(12) Ahmed, N. A.; Kitaigorodskii, A. I.; Mirskaya, K. V. Acta Crystal. B 1971, $27,867$.

(13) Ermer, O. J. Am. Chem. Soc. 1988, 110, 3747.

(14) Guo, W.; Galoppini, E.; Gilardi, R.; Rydja, G. I.; Chen, Y.-H. Crystal Growth Des. 2001, $1,231$.

(15) Roy, S.; Mahata, G.; Biradha, K. Crystal Growth Des. 2009, 9, 5006.

(16) Ryan, P. E.; Lescop, C.; Laliberte, D.; Hamilton, T.; Maris, T.; Wuest, J. D. Inorg. Chem. 2009, 48, 2793.

(17) Ermer, O.; Kusch, A.; Robke, C. Helv. Chim. Acta 2003, 86, 922.

(18) Hu, D.; Kluger, R. Org. Biomol. Chem. 2008, 6, 151.

(19) Tomalia, D. A.; Baker, H.; Dewald, J.; Hall, M.; Kallos, G.; Martin, S.; Roeck, J.; Ryder, J.; Smith, P. Polymer J. 1985, 17, 117.

(20) Hawker, C. J.; Frechet, J. M. J. J. Am. Chem. Soc. 1990, 112, 7638. 
(21) Newkome, G. R.; Moorefield, C. N.; Vögtle, F. Dendrimers and Dendrons. Concepts, Syntheses, Applications 2002.

(22) Vogtle, F.; Gestermann, S.; Hesse, R.; Schwierz, H.; Windisch, B. Progress Polym. Sci. 2000, 25, 987.

(23) Frechet, J. M. J. Proc. Nat. Acad. Sci. USA 2002, 99, 4782.

(24) Hoskins, B. F.; Robson, R. J. Am. Chem. Soc. 1990, 112, 1546.

(25) Grimm, M.; Kirste, B.; Kurreck, H. Angew. Chem. 1986, 98, 1095.

(26) Cheon, E. C.; Suh, M. P. Chem. Eur. J. 2008, 14, 3961.

(27) Reddy, D. S.; Craig, D. C.; Desiraju, G. R. J. Am. Chem. Soc. 1996, 118, 4090. 